\title{
Predominant Improvement of Alpha Cell Function after Steroid Therapy in a Patient with Autoimmune Pancreatitis: Case Report
}

\author{
Ken Takeshima · Hiroyuki Ariyasu (D) Hiroshi Iwakura • \\ Shintaro Kawai · Shinsuke Uraki · Hidefumi Inaba · Machi Furuta • \\ Kenji Warigaya · Shin-ichi Murata · Takashi Akamizu
}

Received: March 25, 2018 / Published online: May 3, 2018

(C) The Author(s) 2018

\begin{abstract}
Introduction: Autoimmune pancreatitis (AIP) is a subset of inflammatory pancreatic disease, responsive to corticosteroid therapy. It is prone to being affected by diabetes mellitus, but the effectiveness of steroid therapy on pancreatic endocrine function is still controversial. We present a case of AIP, focusing on pancreatic endocrine function after steroid therapy.

Case Report: The patient was referred to our hospital with exacerbation of diabetic control and pancreatic swelling. By admission, the insulin secretory capacity was severely impaired. The patient was diagnosed with AIP and treated with prednisolone, resulting in marked improvement of the pancreatic swelling. Glycemic control worsened transiently
\end{abstract}

Enhanced digital features To view enhanced digital features for this article go to https://doi.org/10.6084/ m9.figshare.6148916.

K. Takeshima · H. Ariyasu ( $\square) \cdot$ H. Iwakura •

S. Kawai - S. Uraki - H. Inaba - T. Akamizu

First Department of Internal Medicine, Wakayama

Medical University, Wakayama, Japan

e-mail: ariyasu@wakayama-med.ac.jp

M. Furuta

Department of Laboratory Medicine, Wakayama

Medical University, Wakayama, Japan

K. Warigaya $\cdot$ S. Murata

Department of Human Pathology, Wakayama

Medical University, Wakayama, Japan after initiation of steroid therapy, but insulin requirements decreased along with tapering prednisolone dosage. Pancreatic cytology showed that the acinar structure had been destroyed, and the islets had disappeared. Insulin and glucagon immunostaining revealed slightly scattered alpha and beta cells within the fibrotic stroma. The patient notably showed improved pancreatic alpha cell function predominantly after steroid therapy, despite partial improvement of beta cell function.

Conclusion: An imbalance between alpha and beta cell function may contribute to insufficient diabetic control in some patients with AIP. The pancreatic endocrine function test in combination with pancreatic cytology could be helpful when considering the treatment strategy for diabetic control in patients with AIP.

Keywords: Alpha cell; Autoimmune pancreatitis (AIP); Diabetes mellitus (DM); Glucagon; IgG4related disease (IgG4-RD)

\section{INTRODUCTION}

AIP is a subset of inflammatory pancreatic disease, characterized by diffuse or focal pancreatic swelling responsive to corticosteroid therapy [1]. There are two types of AIP depending on pathologic features: lymphoplasmacytic sclerosing pancreatitis (type 1) and granulocytic epithelial lesions (type 2). 
Immunoglobulin G4-related disease (IgG4$\mathrm{RD})$ is a recently proposed clinical entity [2]. The condition is characterized by elevated serum IgG4 levels, IgG4-positive plasmacytes, and lymphocyte infiltration into multiple organs, resulting in tissue fibrosis and organ dysfunction. In addition to the pancreas, the lacrimal gland, salivary gland, thyroid gland, biliary duct, and retroperitoneal tissue can also be involved in this disease $[3,4]$. Type 1 AIP is considered a pancreatic manifestation of IgG4RD [5].

Approximately $40-80 \%$ of AIP is reported to be associated with diabetes mellitus [6-9]. Although improvement of insulin secretion has been reported [10-12], contrarily, worsening of insulin resistance after steroid therapy has also been reported [6]. Thus, the effectiveness of corticosteroids in pancreatic endocrine function remains controversial. The function of beta cells has been examined, but alpha cell function has never been evaluated before and after steroid therapy in AIP.

To the best of our knowledge, this is the first report of AIP with predominant improvement of alpha cell function after steroid therapy; it suggests that an imbalance between alpha and beta cell functions contributes to insufficient diabetic control in some patients with AIP. Pancreatic endocrine function tests in combination with pancreatic cytology could be helpful for the treatment of diabetes mellitus in AIP.

\section{CASE REPORT}

A 73-year-old male was referred to our hospital with worsening diabetes mellitus and pancreatic swelling. He had a history of hypertension, brain infarction, and atrial fibrillation. His son also has diabetes mellitus. He had been diagnosed with type 2 diabetes mellitus 30 years previously and treated with oral hypoglycemic agents. His diabetes has been well controlled with HbA1c levels between 6 and 7\%. The patient has non-proliferative diabetic retinopathy, but no diabetic nephropathy or neuropathy. He had lost his appetite 7 months before referral and lost $10 \mathrm{~kg}$ bodyweight over 6 months. Diabetic control had worsened
3 months prior with $\mathrm{HbA1c}$ levels of $12.6 \%$, and insulin therapy was started by his family physician. To control for malignancy, computed tomography (CT) was performed, showing diffuse swelling of the pancreas.

On admission, the patient's general condition was fair, and he had no abdominal or back pain. The body mass index (BMI) was $19.6 \mathrm{~kg} /$ $\mathrm{m}^{2}$ and blood pressure was $121 / 80 \mathrm{mmHg}$. He was hospitalized in our department, and basalbolus insulin therapy was initiated under a $1700-\mathrm{kcal} /$ day diet calculated by BMI $(28.7 \mathrm{kcal} /$ $\mathrm{kg})$. Pre-prandial blood glucose levels fluctuated severely between 50 and $300 \mathrm{mg} / \mathrm{dl}$, and 12 units/day of human insulin was needed to maintain blood glucose. Blood tests showed insufficient insulin secretion: fasting plasma blood glucose, $141 \mathrm{mg} / \mathrm{dl}$; plasma C-peptide (CPR), $0.14 \mathrm{ng} / \mathrm{ml}$; CPR index (CPI), 0.14; urinary CPR, $4.1 \mu \mathrm{g} /$ day (Table 1 ).

Abdominal ultrasonography and contrastenhanced CT imaging showed diffuse swelling of the pancreas and a capsule-like rim around the pancreas, both imaging features typical of AIP (Fig. 1a, b). Magnetic resonance cholangiopancreatography (MRCP) revealed diffuse irregular narrowing of the main pancreatic duct (Fig. 1c, d). ${ }^{18}$ F-FDG PET/CT showed diffuse tracer uptake (SUVmax, 3.22) in the pancreas (Fig. 1e, f). No FDG uptake in extra-pancreatic organs, such as the salivary glands or retroperitoneum, was confirmed.

Endoscopic-ultrasound-guided fine-needle aspiration (EUS-FNA) was performed to differentiate the pancreatic cancer. Pancreatic cytology revealed remarkable lymphoplasmacytic infiltration and fibrosis, a severely destroyed acinar structure, and absence of islets; however, there was no evidence of malignancy (Fig. 2a). IgG4 immunostaining revealed the presence of IgG4-positive plasma cells (Fig. 2b). The total number of IgG4-positive plasma cells was $33 / \mathrm{HPF}$, and the IgG4/CD138 ratio was $82.5 \%$. The anti-CD138 antibody was used to count plasma cells instead of the anti-IgG antibody [13].

Thus, we diagnosed our patient with type 1 AIP $[3,14]$. He was initially treated with prednisolone $35 \mathrm{mg} /$ day $(0.6 \mathrm{mg} / \mathrm{kg})$, which was tapered by $5 \mathrm{mg} /$ day every 2 weeks according to 
Table 1 Laboratory data on admission

Urinalysis

Protein

$(-)$

Glucose

$(-)$

Occult blood

$(-)$

Ketone

Reference range

Hematology

White blood cells

6070

$/ \mathrm{ml}$

(3500-9800)

Red blood cells

$448 \times 10^{4}$

$/ \mathrm{ml}$

(420-550)

Hemoglobin

13.2

$\mathrm{g} / \mathrm{dl}$

(13.5-17.5)

Platelets

$17.9 \times 10^{4}$

$/ \mathrm{ml}$

(13-37)

Blood chemistry

Total protein

6.5

Albumin

3.5

Immunoglobulin G

1704

Immunoglobulin G4

Aspartate aminotransferase

Alanine aminotransferase

Lactate dehydrogenase

Alkaline phosphatase

$\gamma$-Glutamyltranspeptidase

Amylase

Pancreatic amylase

Lipase

Elastase-1

Cholinesterase

Creatine kinase

Blood urea nitrogen

Creatinine

539

20

21

192

131

15

105

9

31

$<80$

193

62

20.0

0.99

Sodium

142

Potassium

3.8

Chloride

Total cholesterol
108

131 $\mathrm{g} / \mathrm{dl}$

$\mathrm{g} / \mathrm{dl}$

$\mathrm{mg} / \mathrm{dl}$

$\mathrm{mg} / \mathrm{dl}$

IU/1

IU/1

IU/1

IU/1

IU/1

IU/1

IU/1

IU/1

IU/1

IU/1

IU/1

$\mathrm{mg} / \mathrm{dl}$

$\mathrm{mg} / \mathrm{dl}$

$\mathrm{mEq} / \mathrm{l}$

(6.7-8.1)

(3.9-4.9)

(870-1700)

(5-117)

(7-38)

(4-44)

(124-222)

(106-322)

(13-64)

(44-132)

(18-53)

(13-49)

(0-300)

(240-496)

(60-290)

(8-20)

(0.53-1.02)

(135-145)

(3.5-5)

(98-107)

(130-219) 
Table 1 continued

\begin{tabular}{llll}
\hline Triglyceride & 44 & $\mathrm{mg} / \mathrm{dl}$ & $(30-150)$ \\
Fasting plasma glucose & 141 & $\mathrm{mg} / \mathrm{dl}$ & $(70-109)$ \\
HbA1c (NGSP) & 10.0 & $\%$ & $(4.9-6.0)$ \\
C-peptide reactivity & 0.20 & $\mathrm{ng} / \mathrm{ml}$ & $(1.1-3.3)$ \\
GADAb & $<5.0$ & $\mathrm{U} / \mathrm{ml}$ & $(<5.0)$ \\
CA19-9 & 71.5 & $\mathrm{U} / \mathrm{ml}$ & $(\leq 37)$ \\
Span-1 & 41.2 & $\mathrm{U} / \mathrm{ml}$ & $(0-30)$ \\
DUPAN-2 & 109 & $\mathrm{U} / \mathrm{ml}$ & $(0-150)$ \\
Urinary chemistry & & & \\
Creatine & 723 & $\mathrm{mg} / \mathrm{day}$ & $(500-1500)$ \\
Sodium & 58 & $\mathrm{mEq} / \mathrm{day}$ & $(70-250)$ \\
Potassium & 29 & $\mathrm{mEq} / \mathrm{day}$ & $(25-100)$ \\
Chloride & 64 & $\mathrm{mEq} /$ day & $(70-250)$ \\
Urinary C-peptide reactivity & 4.1 & $\mu \mathrm{g} / \mathrm{day}$ & $(50-1300)$ \\
\hline
\end{tabular}

NGSP National Glycohemoglobin Standardization Program, GADAb anti-GAD antibody

the international consensus for the treatment of AIP (Fig. 3) [15]. Pancreatic morphology was reevaluated with abdominal ultrasonography and CT scan after 12 weeks of prednisolone treatment, which showed marked improvement of the pancreatic swelling and capsule-like rim around the pancreas (Fig. 3). Prednisolone was tapered to $15 \mathrm{mg} /$ day over 12 weeks without recurrence.

Pancreatic endocrine and exocrine function was evaluated before and after 4 weeks of steroid therapy under adequate glycemic control. Considering the daily variance of blood glucose, we measured fasting plasma glucose (FPG) and C-peptide immunoreactivity (CPR) for several days, shown in the scatterplot; the gradient of the regression line increased after 4 weeks of steroid therapy (Fig. 4a). The CPR index also increased significantly (Fig. $4 b ; p=0.016$, Student's $t$ test, Excel statistics), and the meal tolerance test showed improvement of the change in CPR ( $\triangle \mathrm{CPR}$ ) (Fig. 4c). No recovery of the CPR secretory response was shown by $75 \mathrm{~g}$ OGTT, but the area under the curve (AUC)-CPR increased (Fig. 4d, e). These results suggested partial recovery of beta cell function due to steroid therapy.

An arginine tolerance test (ATT) was also performed to evaluate alpha cell function. Over $30 \mathrm{~min}, 30 \mathrm{~g}$ L-arginine hydrochloride was administered, and plasma glucagon levels were measured at $0,10,20,30,45,60$, and $90 \mathrm{~min}$. Plasma glucagon levels were analyzed using both the conventional Glucagon RIA Kit (R-M; Millipore, Billerica, MA) and E-M sandwich ELISA kit (E-M; Mercodia Glucagon ELISA, Uppsala, Sweden). The plasma glucagon response was low and delayed before treatment; it improved remarkably, however, after 4 weeks of steroid therapy (Fig. 4f, g).

For further assessment of pancreatic islet damage, immunostaining of insulin and glucagon in pancreatic cytology specimens was added; a few beta and alpha cells were scattered 

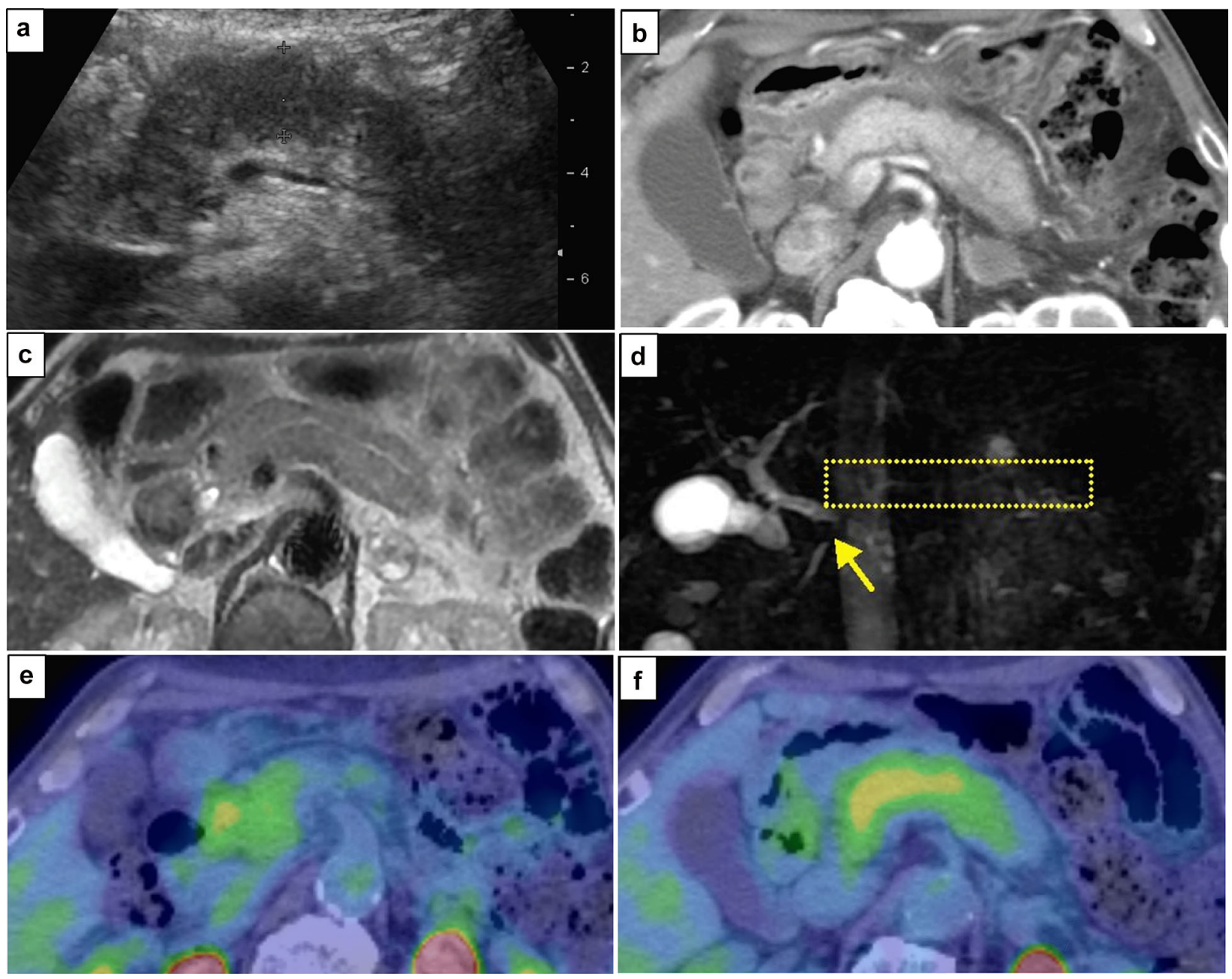

Fig. 1 Imaging findings on admission. Abdominal ultrasonography and the contrast-enhanced CT scan showed diffuse swelling of the pancreas with effacement of the lobular contour (a, b). MRI revealed diffuse irregular

narrowing of the main pancreatic duct and intra-pancreatic bile duct $(\mathbf{c}, \mathbf{d}) .{ }^{18} \mathrm{~F}$-FDG PET/CT showed diffuse tracer uptake in the pancreas with SUVmax of $3.22(\mathbf{e}, \mathbf{f})$

within the fibrotic stroma without intact islet structures (Fig. 2c, d).

Regarding pancreatic exocrine function, pancreatic enzyme levels were low on admission (Table 1 ). In addition, an N-benzoyl-L-tyrosyl-P-aminobenzoic acid (BT-PABA) test was performed before and again 4 weeks after steroid therapy; the excretion rate of p-aminobenzoic acid (PABA) was $23.1 \%$ and $22.4 \%$, respectively (reference value: 73.4-90.4\%). Suggesting no improvement of pancreatic exocrine insufficiency, the patient was

administered pancrelipase $1350 \mathrm{mg} /$ day to treat malabsorption.

The patient needed a maximum insulin dose of 32 units/day after initiating steroid therapy, but the dose was decreased to 21 units/day after prednisolone had been tapered to $15 \mathrm{mg}$ /day with an HbA1c level of $6.7 \%$. Insulin requirements are expected to decline along with prednisolone tapering.

All procedures reported here were in accordance with the ethical standards of the Wakayama Medical University Hospital Ethics Committee and with the 1964 Declaration of 


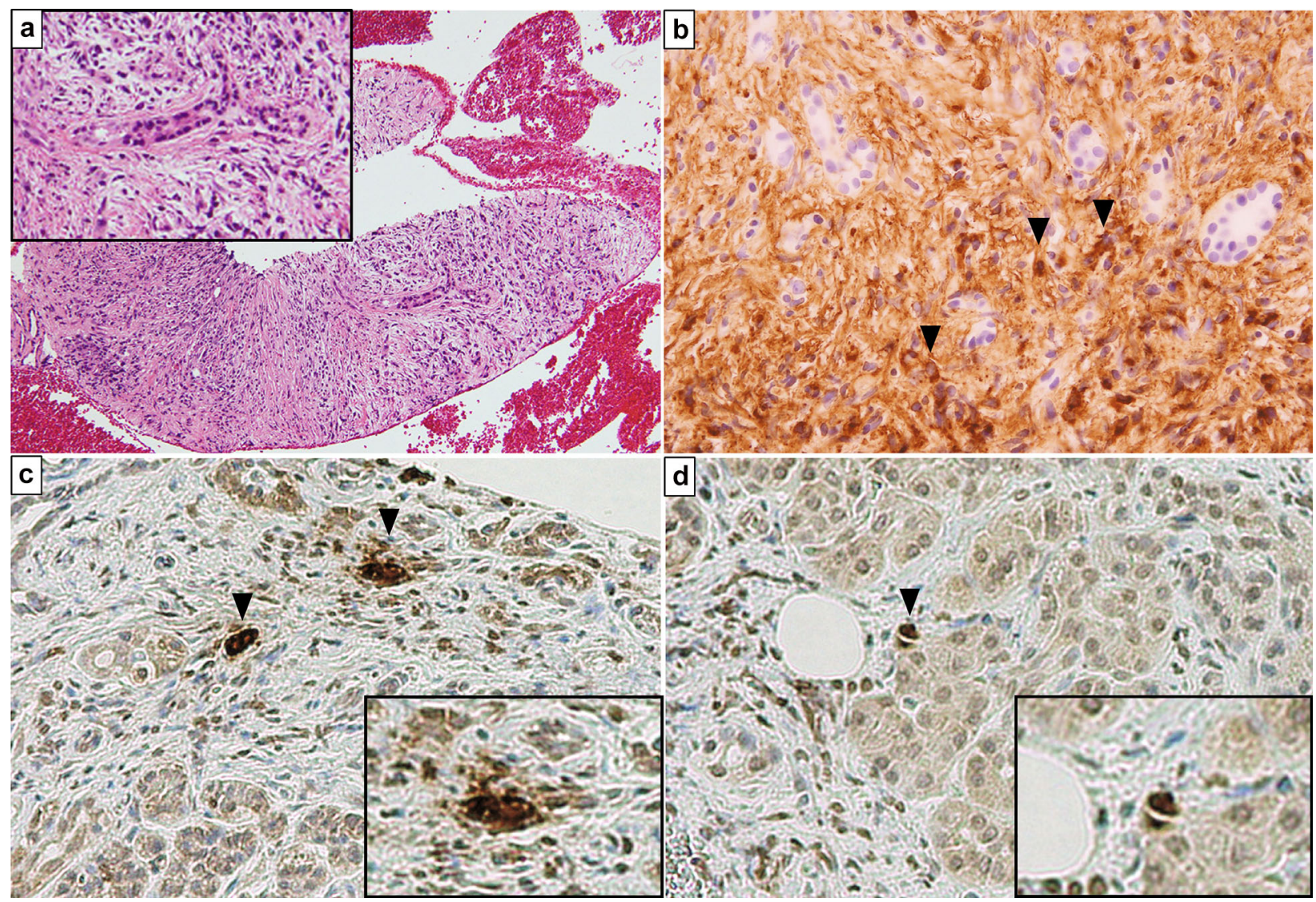

Fig. 2 Endoscopic-ultrasound-guided fine-needle aspiration (EUS-FNA) cytology features of the pancreas. Hematoxylin and eosin staining of the pancreas showed remarkable lymphoplasmacytic infiltration and fibrosis (a). The pancreatic acinar structure had been destroyed, and islets were absent. IgG4 immunostaining revealed the

Helsinki and its later amendments or comparable ethical standards. Informed consent was obtained from all subjects in the case report included in the study.

\section{DISCUSSION}

Our patient was being treated for diabetes mellitus and newly diagnosed with AIP when diabetic control worsened. In previous reports, approximately $30-40 \%$ of AIP patients with diabetes mellitus had a history of diabetic treatment before AIP onset $[6,16]$. Importantly, the worsening of diabetic control can lead to an AIP diagnosis. presence of IgG4-positive plasma cells (b). The total number of IgG4-positive plasma cells was 33/HPF, and the IgG4/CD 138 ratio was $82.5 \%$. Insulin (c) and glucagon (d) immunostaining revealed slightly scattered $\beta$ - and $\alpha$ cells within the fibrotic stroma. Filled downward triangles indicate positive cells for each immunostaining

Tanaka et al. first reported recovery of pancreatic endocrine function in AIP [10]. They assessed beta cell function before and after steroid therapy using $75 \mathrm{~g}$ OGTT and reported that the insulin response improved after steroid therapy. Approximately $13 \%$ of AIP patients had improved glucose tolerance after steroid therapy [12]. In this report, patients with a low insulin secretory capacity before treatment could not be freed from insulin after steroid therapy.

Our patient showed severe destruction of the insulin secretory capacity on admission. Although endocrine function tests revealed partial recovery of beta cell function after 4 weeks of steroid therapy, it was not enough to 


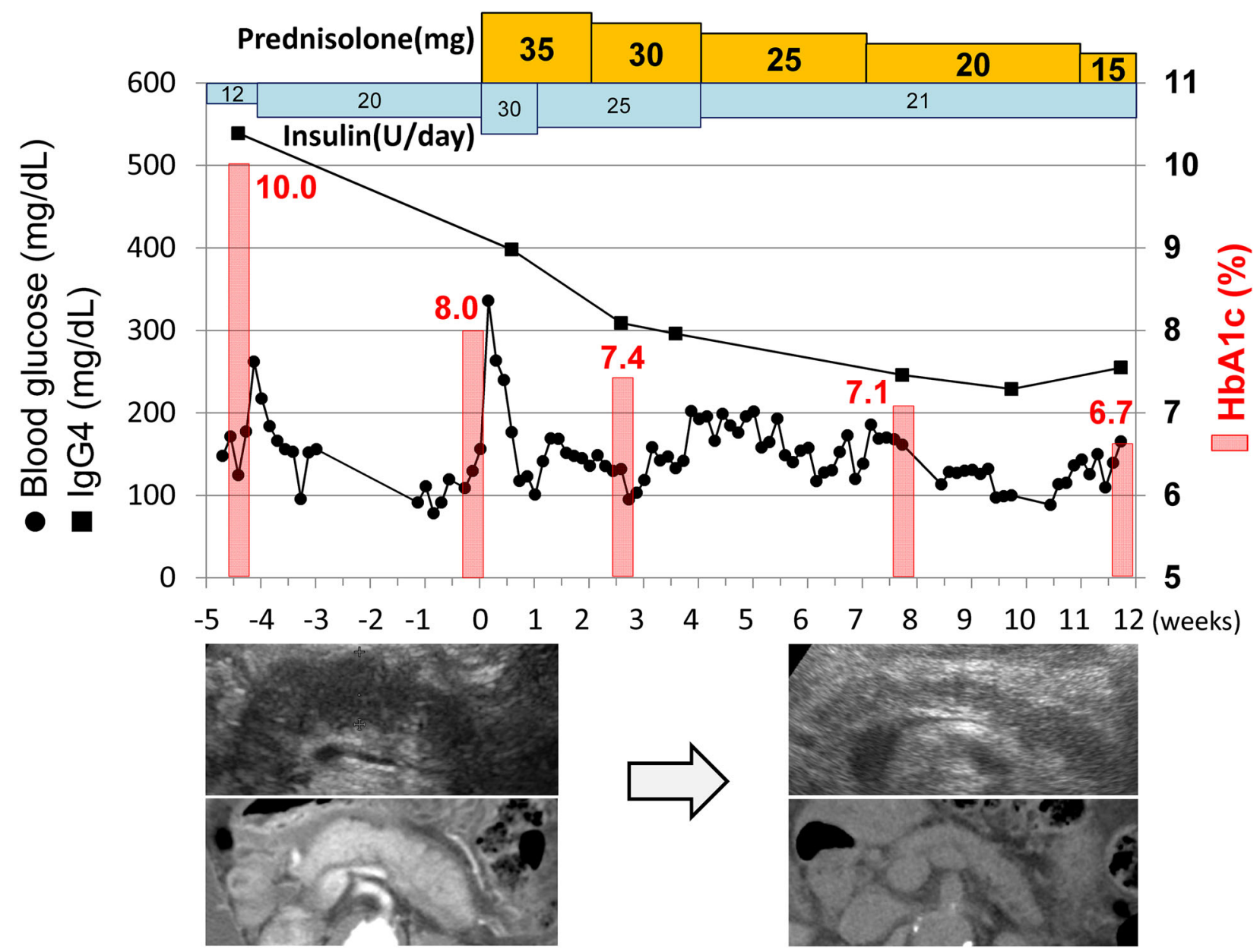

Fig. 3 Diabetic control and clinical course of AIP during steroid therapy. Mean daily pre-prandial blood glucose (closed circle), serum IgG4 levels (closed square), and HbAlc levels (red bar) were measured during treatment with prednisolone. Glycemic control worsened transiently

stop insulin therapy. This outcome is consistent with a previous report [12].

ATT is one of the tests to assess alpha cell function via measurement of the glucagon secretory capacity [17]. In diabetic patients, glucagon hypersecretion after arginine administration has been reported [18]. Our patient had had long-standing diabetes before the occurrence of AIP, so some of the changes in alpha and beta cell function and pancreatic cytology could be attributed to that. Alpha cell function, however, had been destroyed at the onset of AIP, which is more characteristic of AIP than diabetes mellitus [19]. after initiation of steroid therapy; however, it improved as prednisolone was tapered. After 12 weeks of steroid therapy, CT imaging showed marked improvement of the pancreatic swelling. Serum IgG4 levels also decreased without a relapse of AIP

The patient notably showed remarkable improvement in the glucagon response to arginine just 4 weeks after starting steroid therapy, so the changes in pancreatic endocrine conditions could be mainly attributed to AIP. As far as we know, the recovery of alpha cell function has never been reported in AIP.

This implies that alpha cell function is more likely to improve than beta cell function. An imbalance between alpha and beta cell function could therefore occur, which may contribute to insufficient diabetic control. Glucagon inhibitory agents could be a potential treatment option in some patients with AIP; however, 

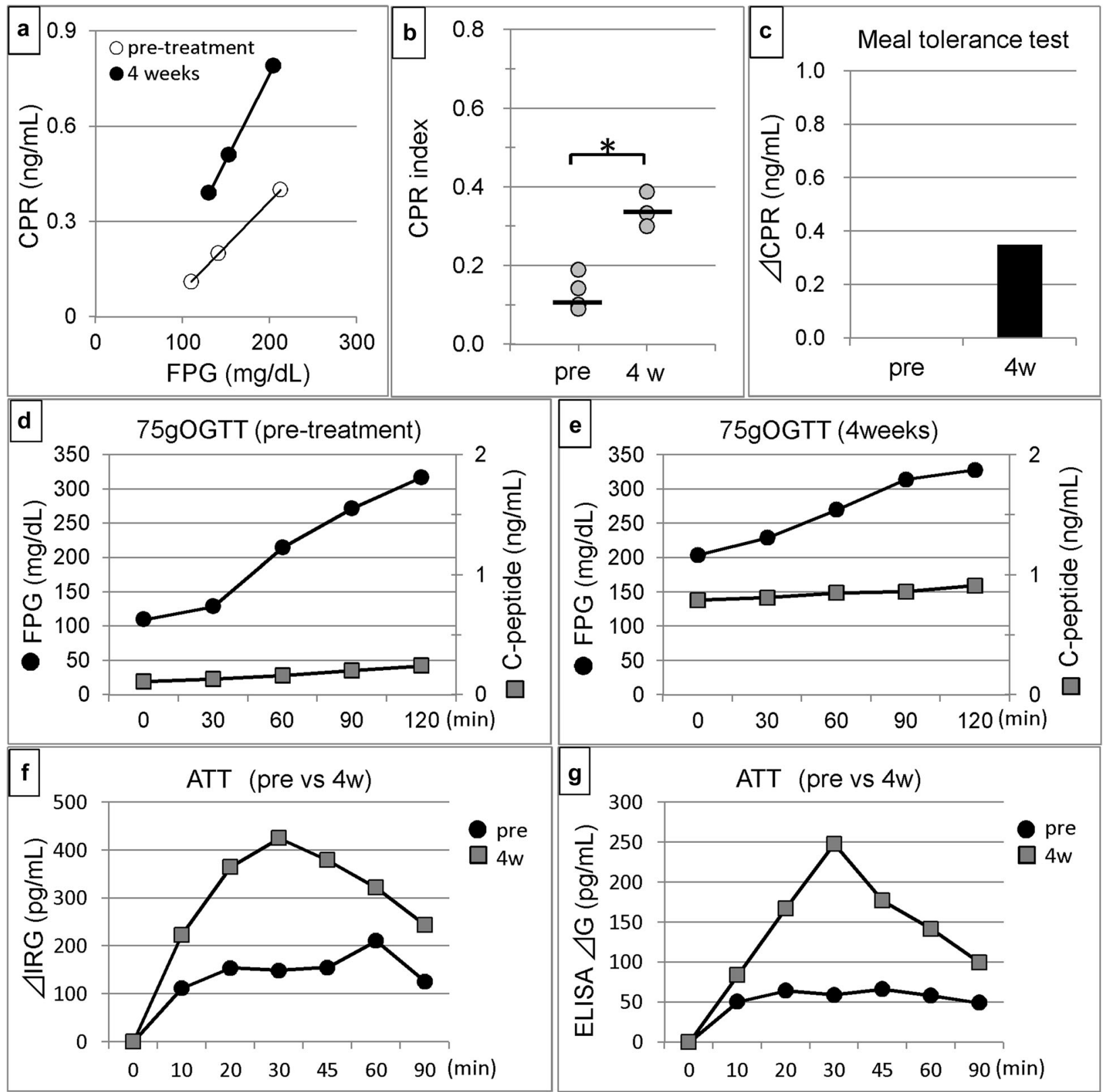

Fig. 4 Pancreatic endocrine function compared before and after steroid therapy. The gradient of the regression line between FPG and CPR (a), the CPR index (b), and $\triangle \mathrm{CPR}$ in the meal tolerance test (c) improved after 4 weeks of steroid therapy. Recovery of the CPR secretory response was not shown by $75 \mathrm{~g}$ OGTT, but the area

under the curve (AUC)-CPR improved after steroid therapy (d, e). ATT showed remarkable improvement of glucagon secretion, which was measured using both conventional radioimmunoassay (f) and the sandwich ELISA kit (g)

studies of more patients are needed to confirm these findings.

In our patient, blood glucose had fluctuated severely with insulin therapy before admission;

he had hypoglycemic episodes and needed to take glucose tablets. After starting treatment with PSL, the number of hypoglycemic events decreased, which contributed to the 
improvement of glycemic control. Recovery of alpha cell function could help avoid hypoglycemic events. Also, partial recovery of insulin secretion might contribute to stabilization of blood glucose.

In Japan, radioimmunoassay kits have been used to measure glucagon. This conventional kit uses a polyclonal antibody recognizing the C-terminal region of glucagon, which could cross-react with the glucagon-like peptides secreted by the intestine. Recently, a more pancreatic glucagon-specific sandwich ELISA kit (Mercodia Glucagon ELISA) became available in our country, so we used it to reanalyze the plasma glucagon levels [18]. Both kits showed marked improvement of glucagon secretion after steroid therapy (Fig. 4f, g).

Pancreatic pathology of type 1 AIP is characterized by remarkable fibrosis and inflammatory cell infiltration surrounding acinar and ductal cells [20]. Although some islets are infiltrated with mononuclear cells with disruption, the majority of islets are reportedly preserved [10]. In addition, beta cell volume decreases in AIP compared with diabetic patients, but the alpha cell volume is the same as that of diabetic patients [21].

In our patient, the pancreatic cytology features as well as endocrine function tests suggested severe destruction of the islets. This result can explain why our patient is still in an insulin-dependent state after treatment with steroid therapy. We judged that the pancreatic cytology specimen had sufficient volume to evaluate the islet structure in our patient, but the limitations of the EUS-FNA specimen, such as sample quality and technical errors, should be considered.

Another possible factor affecting pancreatic endocrine function is cytokines. In patients with IgG4-RD, inflammatory cells infiltrate organs, resulting in enlargement of the organs and fibrosis. The cytokine profile is type 2 helper $\mathrm{T}$ (Th2)-predominate, which activates eosinophilia, IgG4 and IgE production, and fibrosis [2]. Regarding the association of cytokines and insulin secretion, focal or systemic inflammatory cytokines cause beta cell dysfunction [22]. Although the association between cytokines and pancreatic endocrine dysfunction in AIP is reported, further evaluation is needed [10]. Unfortunately, in our patient, cytokine levels were not assessed.

Glucose intolerance in AIP is complicated by multiple factors, including the degree of pancreatic islet damage, cytokines, the balance between alpha and beta cell function, and corticosteroid-induced insulin resistance. Prediction of the recovery of pancreatic endocrine function before steroid therapy in patients with AIP is an issue for future study.

\section{CONCLUSION}

We report AIP with predominant improvement of alpha cell function after steroid therapy. This result suggests an imbalance between alpha and beta cell function contributing to insufficient diabetic control in AIP after steroid therapy. Pancreatic endocrine function tests in combination with pancreatic cytology could be helpful in determining an adequate treatment strategy for diabetes mellitus associated with AIP.

\section{ACKNOWLEDGEMENTS}

The authors are grateful to the patient for his kind contribution to this report.

Funding. No funding or sponsorship was received for this study or publication of this article. The article processing charges were funded by the authors.

Editorial Assistance. We also thank Dr. Yuta Ishiyama and Yuina Akagi for helping with our clinical practice and Benjamin Phillis from Wakayama Medical University for assistance with the English language editing.

Authorship. All named authors meet the International Committee of Medical Journal Editors (ICMJE) criteria for authorship for this article, take responsibility for the integrity of the work as a whole, and have given their approval for this version to be published. 
Disclosures. Ken Takeshima, Hiroyuki Ariyasu, Hiroshi Iwakura, Shintaro Kawai, Shinsuke Uraki, Hidefumi Inaba, Machi Furuta, Kenji Warigaya, Shin-ichi Murata, and Takashi Akamizu have nothing to declare.

Compliance with Ethics Guidelines. All procedures reported here were in accordance with the ethical standards of the Wakayama Medical University Hospital Ethics Committee and with the 1964 Declaration of Helsinki and its later amendments or comparable ethical standards. Informed consent was obtained from all the subject of the case report included in the study.

Data Availability. Data sharing is not applicable to this article, as no data sets were generated or analyzed during the current study.

Open Access. This article is distributed under the terms of the Creative Commons Attribution-NonCommercial 4.0 International License (http://creativecommons.org/licenses/ by-nc/4.0/), which permits any noncommercial use, distribution, and reproduction in any medium, provided you give appropriate credit to the original author(s) and the source, provide a link to the Creative Commons license, and indicate if changes were made.

\section{REFERENCES}

1. Shimosegawa T, Chari ST, Frulloni L, et al. International consensus diagnostic criteria for autoimmune pancreatitis: guidelines of the International Association of Pancreatology. Pancreas. 2011;40:352-8.

2. Stone JH, Zen Y, Deshpande V. IgG4-related disease. N Engl J Med. 2012;366:539-51.

3. Umehara H, Okazaki K, Masaki Y, et al. Comprehensive diagnostic criteria for IgG4-related disease (IgG4-RD), 2011. Mod Rheumatol. 2012;22:21-30.

4. Takeshima $\mathrm{K}$, Inaba $\mathrm{H}$, Ariyasu $\mathrm{H}$, et al. Clinicopathological features of Riedel's thyroiditis associated with IgG4-related disease in Japan. Endocr J. 2015;62:725-31.
5. Hamano H, Kawa S, Horiuchi A, et al. High serum IgG4 concentrations in patients with sclerosing pancreatitis. N Engl J Med. 2001;344:732-8.

6. Nishimori I, Tamakoshi A, Kawa S, et al. Influence of steroid therapy on the course of diabetes mellitus in patients with autoimmune pancreatitis: findings from a nationwide survey in Japan. Research Committee on Intractable Pancreatic Diseases, the Ministry of Health and Welfare of Japan. Pancreas. 2006;32:244-8.

7. Nishino T, Toki F, Oyama H, Shimizu K, Shiratori K. Long-term outcome of autoimmune pancreatitis after oral prednisolone therapy. Intern Med. 2006;45:497-501.

8. Maire F, Le Baleur Y, Rebours V, et al. Outcome of patients with type 1 or 2 autoimmune pancreatitis. Am J Gastroenterol. 2011;106:151-6.

9. Miyamoto Y, Kamisawa T, Tabata T, et al. Short and long-term outcomes of diabetes mellitus in patients with autoimmune pancreatitis after steroid therapy. Gut Liver. 2012;6(4):501-4.

10. Tanaka S, Kobayashi T, Nakanishi K, et al. Corticosteroid-responsive diabetes mellitus associated with autoimmune pancreatitis. Lancet. 2000;356:910-1.

11. Ketikoglou IG, Elefsiniotis IS, Vezali EV, Moulakakis AM. Diabetes mellitus responsive to corticosteroids in autoimmune pancreatitis. J Clin Gastroenterol. 2004;38:910.

12. Hirano $\mathrm{K}$, Isogawa $\mathrm{A}$, Tada $\mathrm{M}$, et al. Long-term prognosis of autoimmune pancreatitis in terms of glucose tolerance. Pancreas. 2012;41:691-5.

13. Mizushima I, Yamada K, Harada K, et al. Diagnostic sensitivity of cutoff values of IgG4-positive plasma cell number and IgG4-positive/CD138-positive cell ratio in typical multiple lesions of patients with IgG4-related disease. Mod Rheumatol. 2017. https://doi.org/10.1080/14397595.2017.1332540.

14. Okazaki K, Kawa S, Kamisawa T, et al. Japanese clinical guidelines for autoimmune pancreatitis. Pancreas. 2009;38:849-66.

15. Okazaki K, Chari ST, Frulloni L, et al. International consensus for the treatment of autoimmune pancreatitis. Pancreatology. 2017;17:1-6.

16. Miyazawa $M$, Takatori $H$, Shimakami $T$, et al. Prognosis of type 1 autoimmune pancreatitis after corticosteroid therapy-induced remission in terms of relapse and diabetes mellitus. PLoS One. 2017. https://doi.org/10.1371/journal.pone.0188549 (eCollection 2017). 
17. Unger RH, Aguilar-Parada E, Müller WA, Eisentraut AM. Studies of pancreatic alpha cell function in normal and diabetic subjects. J Clin Invest. 1970;49:837-48.

18. Matsuo T, Miyagawa J, Kusunoki Y, et al. Postabsorptive hyperglucagonemia in patients with type 2 diabetes mellitus analyzed with a novel enzymelinked immunosorbent assay. J Diabetes Investig. 2016;7:324-31.

19. Ito T, Kawabe K, Arita Y, Hisano T, et al. Evaluation of pancreatic endocrine and exocrine function in patients with autoimmune pancreatitis. Pancreas. 2007;34:254-9.
20. Farris AB 3rd, Lauwers GY, Deshpande V. Autoimmune pancreatitis-related diabetes: quantitative analysis of endocrine islet cells and inflammatory infiltrate. Virchows Arch. 2010;457:329-36.

21. Tanaka S, Kobayashi T, Nakanishi K, et al. Evidence of primary beta-cell destruction by $\mathrm{T}$-cells and betacell differentiation from pancreatic ductal cells in diabetes associated with active autoimmune chronic pancreatitis. Diabetes Care. 2001;24:1661-7.

22. Rabinovitch A. An update on cytokines in the pathogenesis of insulin-dependent diabetes mellitus. Diabetes Metab Rev. 1998;14:129-51. 